This item was submitted to Loughborough's Research Repository by the author.

Items in Figshare are protected by copyright, with all rights reserved, unless otherwise indicated.

\title{
Empirical evaluation of a technology acceptance model for mobile policing
}

PLEASE CITE THE PUBLISHED VERSION

http://dx.doi.org/10.1080/15614263.2013.829602

\section{PUBLISHER}

(c) Taylor and Francis

\section{VERSION}

AM (Accepted Manuscript)

\section{PUBLISHER STATEMENT}

This work is made available according to the conditions of the Creative Commons Attribution-NonCommercialNoDerivatives 4.0 International (CC BY-NC-ND 4.0) licence. Full details of this licence are available at: https://creativecommons.org/licenses/by-nc-nd/4.0/

\section{LICENCE}

CC BY-NC-ND 4.0

\section{REPOSITORY RECORD}

Lindsay, Rachael, Thomas Jackson, and Louise Cooke. 2019. "Empirical Evaluation of a Technology Acceptance Model for Mobile Policing”. figshare. https://hdl.handle.net/2134/14632. 
This item was submitted to Loughborough's Institutional Repository (https://dspace.lboro.ac.uk/) by the author and is made available under the following Creative Commons Licence conditions.

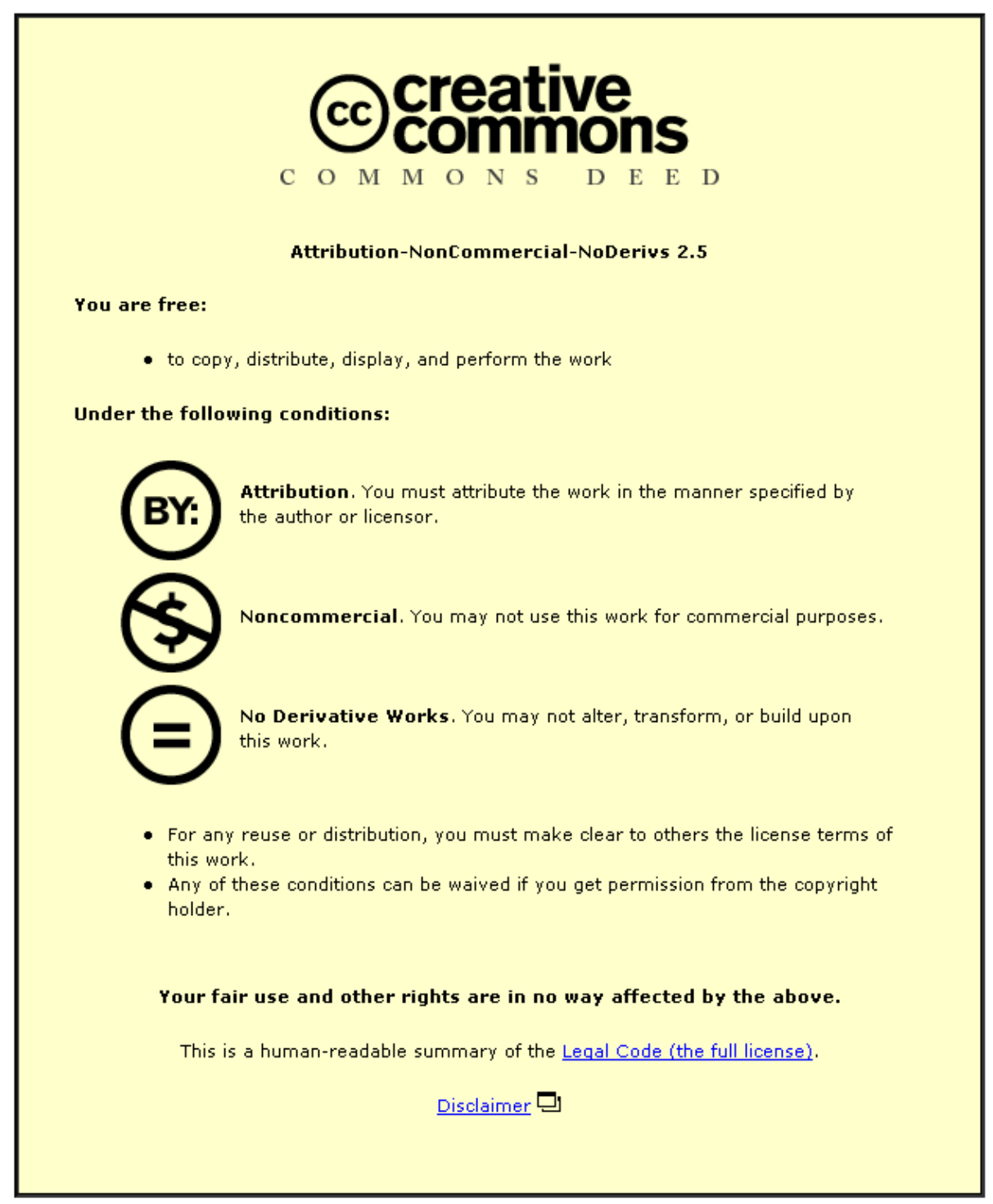

For the full text of this licence, please go to: http://creativecommons.org/licenses/by-nc-nd/2.5/ 


\title{
Empirical Evaluation of a Technology Acceptance Model for Mobile Policing
}

\author{
Rachael Lindsay \\ Thomas W. Jackson* \\ Louise Cooke \\ Department of Information Science \\ Loughborough University, Loughborough, Leicestershire, United Kingdom, LE11 3TU \\ *t.w.jackson@lboro.ac.uk
}

\begin{abstract}
Technology acceptance in policing is under-researched, yet mobile devices are widely implemented across UK police forces. The paper validates a mobile technology acceptance model (M-TAM), developed in a single police force. It shows that the M-TAM is transferrable to other UK police Forces, and potentially worldwide. The influence of local supervision and fit of technology to roles and tasks are shown to be the most influential factors. Factors beyond the technology itself, such as the influence of peers and involvement of operational officers in technology investment decisions, must be considered to accommodate the strong cultural barriers in policing.
\end{abstract}

\section{Keywords}

Technology acceptance model; mobile policing; validation; culture; UK police force

\section{Introduction}

This paper tests the relevance of a model (M-TAM) to police forces worldwide, offering a useful tool to implementation of their mobile technology information programme. It evaluates the model using a 'professional review' with a purposive sample of experts. It contributes to knowledge of technology acceptance in policing, building on the original technology acceptance model (TAM) (Davis, 1989). It also contributes to practical evaluation methodologies of theoretical technology acceptance models.

Between 2008 and 2010, the UK government distributed £71 million to English police forces to implement a Mobile Information Programme. It aimed to support greater visibility of police 
officers and reduce bureaucracy through the use of mobile devices (Great Britain, 2012). However, Parliamentary review of the Programme suggests that only one in five forces have used the Programme to improve the efficiency of their business processes. Most police forces have focused on procuring mobile devices at the expense of addressing adoption and implementation factors (Ibid). This issue is consistent with a history of the failure of large-scale IT implementation projects across the public sector (Goldfinch, 2007). The National Policing Improvement Agency estimates that 10\% of the annual UK spend on policing - around $£ 1.5$ billion - is directed towards IT. A better understanding of the factors that lead to successful adoption of technology by police officers is therefore of significant importance.

\section{Background}

Technology implementation management presents a challenge to private and public sector organisations (Lapointe and Rivard, 2005). User technology acceptance is critical to the success of recently implemented IT (Gallivan, 2001) and has seen considerable research in the past 30 years (for example Rogers, 2003; Davis, 1989; Goodhue and Thompson, 1995; Venkatesh et al, 2003). Organisations with an understanding of such factors are more likely to implement complementary conditions that encourage usage of technology. This is increasingly important in the climate of financial austerity. However, despite advances in technology, the problem of under used systems continues (Venkatesh and Davis, 2000).

Recent user acceptance research has moved from business contexts to non-profit organisations, especially government agencies that can use technology to support highly specialised activities. For example, law enforcement agencies rely on police officers to apply specialised information to make time-critical decisions to fight and prevent crime (Luen and Al-Hawamdeh, 2001). To facilitate such decision-making, UK police forces have implemented a national initiative to provide mobile access to police information systems (Arnott, 2007; Flanagan, 2008). Mobile technology acceptance in policing is under-researched (for example Hu et al, 2003; Colvin and Goh, 2005 and Bouwman and van der Wijngaert, 2010). In response, Anon (2011) developed an adapted officer mobile technology 
acceptance model (M-TAM) within a single UK police force (the Leicestershire Constabulary) (see Figure 1). The M-TAM identifies four categories that explain whether police officers embrace or reject mobile technologies: performance; security and reliability; management style; and cognitive acceptance. The latter two M-TAM factors extend Davis’ original theoretical Technology Acceptance Model (TAM) (1989), which considers factors intrinsic to the technology itself. Perceived ease of use (PEOU), for example battery life; and perceived usefulness (PU), such as impact on information availability, cover the original TAM factors.

The original TAM has been subject to much critique, but its applicability is not discussed in a mobile policing context. Bagozzi (2007) for example, critiques the model from a behavioural research perspective, arguing for greater account of factors that influence individual decisionmaking. Lai's work on internet banking (2005) indicates that while the TAM is a mature, extensively validated model, its accuracy across different sub-groups should be further empirically investigated. Our empirical work with operational police officers (Anon, 2011) extends the original TAM by incorporating external factors within the wider implementation and social context. The level of training, officer involvement and information for mobile data terminals (MDTs) are the main factors underlining the management style category. Officer and public perception of MDTs, peer influence and organisational culture influence the level of cognitive acceptance (Anon, 2011). Organisational culture was an important factor in the M-TAM due to the short timescale for officers to adjust to staying out the station and working more self-sufficiently. This may reflect the command nature of policing, where superiors make changes and expect officers to adjust accordingly.

Insert - Figure 1: A Mobile Technology Acceptance Model (Anon, 2011; adapted from Lin et al, 2002)

The M-TAM is a high-level model so could be applied to other policing contexts, regardless of type of mobile device (Anon, 2011). Its validity should be tested beyond a single organisational 
environment to other mobile devices (not just tough books) and other policing contexts. Similar research tested the applicability of the original TAM in policing, but were focused on a specific policing organisation, as shown by Table 1, and did not specifically consider mobile technology adoption and if the model could be generalised to other contexts.

Insert - Table 1: Only single research contexts have been used to examine factors influencing police officer acceptance of technology

Glomseth and Gottschalk (2009) argue that there is no such thing as one single police culture, and it is affected by the organisation, structure and tasks. This is viewed as occupational culture, with accepted principles of conduct that are applied to a variety of situations. For example, Christensen and Crank (2002) found that urban police officers were more concerned with action, risk, excitement and crime fighting than non-urban officers. Such occupational cultural differences may imply that different factors need to be considered in order to maximise the acceptance of new technologies. Consequently, this paper aimed to test the M-TAM within other UK police forces to ensure that it accommodates variations in culture and any police force implementing or about to implement mobile technology can use the M-TAM to address the barriers to user acceptance. The next section discusses the methods used to collect the data, followed by presentation of findings and a discussion of their implications for technology implementation management in mobile policing.

\section{Research Design}

The M-TAM was tested formatively, using a professional review method to determine inconsistencies with the model. A professional review uses five to ten field experts (House, 1980) who have practical, well-regarded knowledge of the issues under investigation (Adler and Ziglio, 1996, Turner, 2001). Expert interviews can efficiently achieve reliable results, with the expert acting as a surrogate for the wider professional circle (Bogner et al., 2009). The most appropriate experts in this research were project managers (PM) overseeing the implementation of mobile technology in 
other UK police forces. Using those with a vested interest in the mobile technology project may introduce bias, but provides the best understanding of implementation issues. Individual evaluation does not consider the impact of the social culture when police officers work together within their own cultural domain, and this may influence the results. Overall the relevance of 'expert evaluation' outweighed the disadvantages of the research strategy.

\section{The research domain}

As per House's guidelines (1980), data was collected on the wider applicability of factors identified within the Leicestershire Constabulary using semi-structured interviews with nine project managers from five UK police forces. Data was also collected from several police force presentations at a workshop facilitated by the UK Home Office (HO), covering lessons learned and barriers to successful implementation of mobile technologies. Thematic analysis was conducted on the presentations (see ‘data analysis’ section). Table 2 shows the research design.

Insert - Table 2: Experts used within the Research Design

The interview questions were guided by adapting Scriven and Coryn’s framework (2008, p. 97):

1. Determine the definition of the evaluator of the terms used in the model;

2. Establish whether the evaluator perceives all elements of the model as equal, or whether some elements are more important;

3. Ascertain if the evaluator agrees with the relationships present, and whether any relationships need adding;

4. Conclude whether the evaluator agrees with the model, if not; determine necessary changes through a second round.

The first part of the interview established what mobile devices the force uses (Q1) and how long they have been in place (Q2). As per step one of the framework, the M-TAM factors were 
explained to experts. For the second step, experts were asked from their experience which elements of the M-TAM they viewed as the least and most important (Q3). To avoid encountering the previously discussed bias from project managers, it was important to use open-ended interview questions, rather than focusing on one specific technology acceptance factor. For steps three and four of the process, experts were asked whether the model encapsulates the experience of mobile technology in their organisation (Q4a), if there was anything that they would change in the model when rolling out mobile technology in their force (Q4b) and if so what they would change (Q4c).

Purposive sampling was used to cover different mobile devices (MDT or handheld) and expertise (length of time the technology had been in use). The sample included the following police forces, types and numbers of device (Q1 and Q2):

- Cheshire Police [PM 1 and PM 2] 1200 PDAs deployed across all of response and neighbourhood teams since September 2008.

- Essex Police [PM 3 and PM 4] 3000 PDAs since January 2007. Functionality is roledependent

- Yorkshire Police collaboration (N. Yorks., W. Yorks. and Humberside Police). [PM 5 and PM 6]. 150 PDAs since 2008.

- Wiltshire Police [PM 7] 900 PDAs/ 'Redfly' devices since April 2009 (Redfly is a large screen and keyboard for PDAs) Remote access to police information systems via broadband computers used in community

- Lancashire Police [PM 8 and PM 9] 3000 PDAs and 200 fixed MDTs since 2000. 200 removable MDTs since Sept 2009.

- Home Office workshop, Ryton, Coventry, Warwickshire (All UK police forces present). Variety of handheld and MDT devices.

\section{Data analysis}

Each interview and presentation was transcribed with consent of the participant. The common user acceptance factors emerging from the transcripts were thematically coded using the qualitative analysis package, Atlas.ti. Coding is the mechanism to place data into themes (Bryman, 2001) that emerge from the data, such as device functionality, information security and user training. Qualitative data analysis software packages such as Atlas.ti can not only speed up the analysis of 
qualitative data, but manage complexity in identifying relationships within qualitative datasets (Barry, 1998). Any new themes or factors from the data outside the M-TAM were coded as a new user acceptance factor. A thematic grid or matrix was used for each theme to draw conclusions over common findings.

Content analysis was used to identify the frequency of factors within the coded dataset, using Atlas.ti (Bryman and Hardy, 2009). Miles and Huberman (1994) argue that numerical analysis can sometimes reduce the ambiguity of qualitative datasets. By reducing the interview transcripts and identifying common patterns, the M-TAM could be validated in a clear way. In order to avoid loss of richness of data, Bryman and Hardy (2009) recommend keeping any words and numerical data together in the analysis. The following section discusses the results of the professional review and content analysis.

\section{Results and Discussion:}

This section discusses the existing M-TAM factors that were relevant to other police forces and the newly emerging user acceptance factors. It then presents a revised M-TAM from the evaluation and discusses its practical applicability within a wider policing context.

\section{Content analysis themes: the applicability of the M-TAM}

Table 3 shows the results of the content analysis performed on the data from the expert evaluation. It is evident that within a wider policing context the most influential overall officer acceptance factors are: -

- Level of information provided about mobile technology (13.06 per cent of all data);

- Level of training (10.81 per cent of all data);

- Level of officer involvement in decision-making (10.36 per cent of all data);

- Reliability (8.11 per cent of all data);

- Peer influence (8.11 per cent of all data);

- Officer efficiency (6.76 per cent of all data);

- Functionality of the device (5.86 per cent of all data). 
Most of these factors are external. This supports the notion that wider implementation issues, not intrinsic to the mobile device and not part of Davis’ TAM, must be considered to increase PEOU and PU (see Introduction). The least frequent factors within the content analysis are internal factors, including data quality (less than one per cent of all data), inputting information via a mobile device (less than one per cent of all data) and security of the device (1.80 per cent of all data).

Insert - Table 3: Content analysis of factors within the M-TAM from a professional review of other UK police forces (N.B. figures refer to frequency of factors within the interview transcripts)

Out of the four overall themes, the most frequent was management style (40.5 per cent of all data). Officer performance covered 26.62 per cent of all data, cognitive acceptance 21.62 per cent of all data, and security/reliability/usability included 14.86 per cent of all data. The extent of management style factors during the implementation process may be less surprising within a hierarchical command organisational structure. However, these results suggest that intrinsic PU resulting from the officer efficiency factors is also an important influence on officer acceptance.

Interestingly, personal factors such as officer age did not emerge from the empirical data, in contrast to other work on technology acceptance (Porter and Donthu, 2006). Although the use of percentages does not provide an in-depth picture, and the small sample size reduces the usefulness of this form of data representation, it still provides pointers towards the common factors within a wider policing context.

\section{Qualitative evidence from expert review: factors included in M-TAM}

This section examines: the qualitative expert review evidence for the common factors within each category of the M-TAM (Q3); new factors emerging from the data analysis (Q4b and Q4c); and the overall applicability of the M-TAM within policing (Q4a). 


\section{a. Operational performance}

Experts were asked from their experience which elements of the M-TAM they viewed as least and most important (Q3). Within the operational performance category, the two most important factors were the functionality of mobile devices and the impact of mobile technology on officer efficiency. The 'officer efficiency' factor related to direct access to information for purposes of identification and updates, resulting in a greater number of arrests and thus an increase in the PU of mobile technology.

In addition to the mobile technology improving the identification process, PM 2 from the Cheshire Police suggested that mobile technology allowed officers to save time when updating details and this had a positive impact on PU:

What typically happens is if an officer attends a missing persons incident, they will be dispatched to the address of the parents/ care home etc and take a photograph of the missing child, then drive all the way back to the station, scan the photo and attach it to the document, which will then be available to all officers to download. Instead, an officer can take a photograph on the PDA and ping it out to all officers - (PM 2, Cheshire Police).

However, PMs 3 and 5 were less positive, suggesting mobile technologies could act as a means of monitoring what police officers are doing and remove an element of trust. This might reduce PU of mobile technology.

Issues were raised about a shortage of device functionality. These included a lack of access to additional systems and the removal of the telephony feature from the handheld devices. In addition, PM 5 within the Yorkshire Police Collaboration commented on a poor input interface: 
Yeah, these are our devices [shows PDA]; it doesn't actually come with a flip-out keyboard...it's still top-pocket technology in terms of policing but you wouldn't slip it in your back pocket and take it down the pub in your jeans...but if this did come with a slip-out keyboard then the same people who are complaining about the on-screen keyboard would be complaining about the bulkiness of the device. - (PM 5, Yorkshire Police Collaboration).

As per the study in the Leicestershire Constabulary, a common issue negatively affecting PU of mobile devices throughout UK police forces was the lack of access to systems (Anon, 2011). Despite this, some experts commented that PU can be increased by acting on user feedback, such as increasing the functionality. The impact of these two factors on officer performance and thus PU strongly support the M-TAM findings within the Leicestershire Constabulary. These should be a key focus within the implementation process.

\section{b. Security, reliability and usability}

The content analysis showed that reliability was the main factor negatively affecting PEOU of mobile technology across all police forces studied. This includes issues with connectivity, speed and battery life of the device. Similar to the original M-TAM, the connectivity of mobile devices was a key factor affecting PEOU amongst PMs 4, 6, 9 and workshop participants, for example:

Our county is quite rural so we definitely have issues with connectivity and we are interested to know what Leicestershire are doing to address their issues with poor signal. This is definitely affecting user acceptance amongst some officers - (PM 9, Lancashire Police).

For example, with poor signal in particular areas, if we know about it then we ask our supplier to boost the signal e.g. for V Festival...it's more of a problem for officers travelling at speed. (PM3, Essex Police).

PMs 3, 7 and workshop participants supported the impact of a good battery life on PEOU. In addition, PEOU was also affected by the time required to log on, as common within the M-TAM in the Leicestershire Constabulary: 
For example battery life, some are just duff batteries that don't hold their charge so we issue them with another officer. And if you give a duff battery to an officer and they don't realise it can be rectified, then their PDA just stays in their locker...once they have that thought in their head then they won't use it. - (PM 5, Yorkshire Police Collaboration).

Speed of the device is an issue...I think to myself if I was an officer and I was trying to log onto the PDA at the roadside I'd probably be frustrated with it - (PM3, Essex Police).

These issues, as shown in Figure 1, are already incorporated into the M-TAM and therefore verify the model within a wider policing context.

\section{c. Management style}

Management style factors were the most frequently cited theme in the content analysis, validating the implementation context of the M-TAM. Here, the most common factors were training, officer involvement, and information provided about mobile technology (see Figure 1).

The interviews widely discussed that the small amount of training and lack of real-life scenarios provided during the implementation process had a negative impact on PU, therefore validating this factor of the M-TAM. One police force had addressed this by providing a full practical training package with scenarios and real-life exercises:

We trained the officers how to use the device and the mobile applications over a twoweek period. We used a computer-based programme to teach officers how to navigate around a device. Officers were allocated two hours of their shift to do the computer-based training. Officers use the device during their work time by accessing email and other applications to familiarise themselves with the device. Following the computer-based training, we held a oneday workshop, which was scenario-based. We're not teaching them how to be police officers; 
we're teaching them how the mobile device will help them in certain circumstances to be able to do work in a more effective way, and in the place where an officer needs to do the task. (PM 7, Wiltshire Police)

Alongside the importance of training, project managers 3, 7 and $\mathrm{HO}$ workshop participants supported the officer involvement factor. They stressed the need to promote PU by constantly gaining and acting upon officer feedback during implementation.

The level of information provided to users about mobile technology was the most common factor in the content analysis. Project managers 1, 2, 3, 5, 7, 8 and HO workshop participants emphasised the importance of ensuring that key stakeholders, not just operational officers, such as control room personnel, are kept informed about the core purpose of introducing the technology. Not doing so may have a negative effect on PU of mobile devices:

Well that's in the 'level of information about MDTs' factor isn't it, it's not just telling the officers how to use the technology but why they are using it. It's underpinning the whole thing, because at the end of the day if you haven't got a bloody good reason why you're doing it then all these factors disappear - you don't need a device. I think user acceptance is about getting people brought into that idea. - (PM 1 and 2, Cheshire Police)

Related studies (Anon, 2011; Collerette et al, 2006) demonstrate that change is facilitated by communicating information throughout the development of a new information system.

\section{d. Cognitive factors}

The influence of peers was a common factor within the cognitive theme (Table 3). This factor was particularly influential on PU of MDTs in the M-TAM, where more proficient users acted as 
'super users' to the more change-resistant officers. Other UK police forces reported similar findings, indicating that project champions may be a good way to increase PU amongst users. Close bonds exist within law enforcement, as a result of officers working in teams to solve problems (for example Waddington, 1999, Chan, 1996, Reiner, 1992). The influence of peers is therefore a key factor within the M-TAM:

Having done the training workshop, officers have support through divisional champions who will assist other officers with any difficulties. Members of the project team are operational police officers to provide credibility. They assist with the rollout and do the workshop training, and ask the users for their experiences of how they use the device operationally. (PM 7, Wiltshire Police).

\section{New M-TAM factors}

\section{a. Management style}

Experts were asked in the interviews whether there was anything that they would change in the M-TAM (Q4b) and if so what they would change (Q4c). From the validation, new factors emerged to the original M-TAM and included: local leadership and supervision; senior management buy-in to encourage usage of the devices; and the amount of time to implement mobile technology. This reflects an orientation towards a consultative management style, which favours strong leadership and direction, but within which a manager "sells" rather than "forces" a decision (Tannenbaum and Schmidt, 1973). These factors are extrinsic to the technology and are not accounted for by the original TAM or the M-TAM model. 
The validation consistently highlighted that local supervisors (sergeants) must increase usage by encouraging their officers to use their device and questioning an officer who spends a significant period of time inside their police station.

[PM1] Local factors need to be considered within the TAM model. For example, we didn't get the supervision on board. Even now, local supervision still hasn't got a clue why we are telling officers to use the devices. We are looking to address this now. Officers need their supervisors to kick them out and question why they're in there.

[PM2] Years ago, the sergeant was kicking officers out of the station and asking them why they were back in the station...officers had to ask permission to go back to the station...whereas now IT has dragged them all in and given them a valid reason for coming back in and now officers are set in that way aren't they?

[PM1] Yes...now we have a non-confrontational culture in the police...very ‘soft'...sergeants have two years' service...they've not been told how to supervise in a rigorous way...that's all fallen away...the supervisor wants to be best mates with their team...and they're going to start kicking officers out of their station?!...I don't think so! (PM 1 and PM 2, Cheshire Police).

It was highlighted that publishing usage figures could promote healthy competition between local policing units and increase usage. Project managers 1, 2, 3 and 6 and HO participants suggested that local supervisors want to appear better than other police units by increasing their officers' usage. This may work in the inter-departmental camaraderie of policing.

Three of five participants also indicated that buy-in from senior management can promote usage from the top-down; a key factor in the hierarchical nature of policing. This factor was less 
important in the Leicestershire Constabulary, because senior management were keen to implement MDTs before the Government initiative. Later adopting police forces of mobile technology under the drive from the Government may be less enthusiastic. In less authoritarian organisations this may have a negative effect on user acceptance; which is why the M-TAM is specific to policing organisations. The following comment exemplifies the newly emerging factor:

[The new Chief Constable's]... come in and absolutely kicked arse...turned up at local police stations and said to officers 'what are you doing in here, get out!' The new Chief has had this effect and the officers are really up for it...they're streamlined, they know about visibility...so when a PDA is introduced officers are like 'oh yeah, let's have one of those, I can get out of the station more'. For Forces that don't have that culture, usage will reach a peak and for it to increase any further there needs to be some serious intervention by applying some of the management style factors within your TAM model along with additional things like strong supervision. - (Anonymous).

The short time period to implement mobile technology was a new management style factor from the M-TAM validation. The existing M-TAM partly addressed this, but reflected the time for the organisation to adjust to the cultural change, rather than time to implement mobile devices. The interviews commonly discussed that pressure from the Government to implement mobile devices by the end of 2008 left too short a timeframe and had a negative impact on PU. The following quote demonstrates that this factor needs be incorporated in the M-TAM:

I think what we should've done as well is we should've done everything much more slowly. For example, training a team, learnt some lessons, and adjust the training accordingly...having a feedback cycle - but we had none of that. It was already set in stone...we just blasted out the technology to 1200 users...probably 800 of them were totally 
unequipped to use the devices. - (PM 1, Cheshire Police).

\section{b. Local context}

Several participant police forces have implemented mobile technologies differently to the Leicestershire Constabulary. They tailored the device functionality to the individual roles and tasks. The Leicestershire Police tailored the hardware devices rather than software functionality, by providing MDTs in patrol cars and handheld BlackBerries to foot patrol officers. Access to all police information systems on a MDT increased PU in Leicestershire. However, the entire sample suggested that providing all desktop applications on a MDT had a negative effect on PU. Users may feel overwhelmed with the number of systems on a mobile device, some of which are irrelevant to their job, and so might not use their mobile device:

It is important that the application suits the mobile environment. You've gotta find the killer application for each role. For the MDTs in Leicestershire, it's a mirror of what's on the desktop, so officers have got most of the functionality, but then is that necessarily a good thing because different roles will use different functionalities and it's not tailored to specific roles. (PM 5 and PM 6, Yorkshire Police Collaboration).

To increase PU, all participant police forces tailored the software functionality and training to the systems frequently used in each policing role. For example, a road traffic officer is more likely to need access to online road traffic collision forms than a foot patrol officer:

Some functionality is specific to certain roles, such as fixed penalty notices, which are obviously going to be of most benefit to the road policing unit...At the same time the devices have stop and search forms available, which are more beneficial to the neighbourhood policing roles...so it's about trying to get a balance on there to get something on the device for 
all of them. - (PM 5, Yorkshire Police Collaboration).

Essex Police and Wiltshire Police have also considered when it is appropriate or practical to use a handheld mobile device. For example, it is less practical to input lengthy statements using a handheld device, and this might reduce PU of mobile technology. Instead, an officer might choose to return to their local police station to complete this task. To increase PU and manage the cultural change of encouraging officers to stay on patrol, Essex and Wiltshire Police created remote access to policing information systems in public spaces, such as libraries and local schools. This increased visibility and possibly deterred public disorders: -

We have implemented desktop PCs into our local hospital... rather than wandering around a hospital with a cup of coffee, officers can start prepping a few bits of documentation... and save time at the end of their shift. We are looking to put desktop PCs into schools and courts etc...if an officer is passing a library they might nip in there to do a long task rather than going back to the station... There is a whole raft of doing mobile working, not just a PDA... the options are working in harmony to keep officers out of the station depending on the task they need to do. It's about working out that variety and the best way to deliver the technology for the task. - (PM 3, Essex Police).

Research by Bouwman and van de Wijngaert (2009) supports this finding. It indicates that the context of specific tasks plays a role in the trade-off between PEOU and PU. One participant commented that the working environment of policing is more hostile than those of commercial organisations using mobile devices. This might mean it is more appropriate for a police officer to complete lengthy tasks in a local public library or school, rather than at a home of a victim:

Organisations are very different to police forces. A British Gas engineer is going to a house where he's there to help the people, they will make him a cup of tea and provide him 
with a table and chair to sit down and use his laptop. It's a different environment. - (PM 1, Cheshire Police).

The Essex Police approach might work in police forces with resistance to cultural change associated with encouraging police officers to stay on patrol. Mobile devices can be used in more relevant situations, increasing PU, whilst for lengthier tasks a desktop computer in the community can be used without compromising on visibility.

\section{Practical relevance and applicability of the M-TAM within a wider policing context}

Experts were asked overall whether the model encapsulates the experience of mobile technologies in their organisation (Q4a). Overall, other than some newly emerging factors, the evidence showed that the M-TAM was applicable in other police forces, illustrated by comments such as: -

For me, I recognise everything that is on the model. I mean PM6 is more of your research person for how the model might sit, but for me I can give you a practical perspective as to how the model fits within our experience. I'd say it's pretty much there. I think all the factors from our experience are in the model and I think the links are clear as well. - (PM 5, Yorkshire Police Collaboration).

I actually think that your model sums up all the conversations that we have been having over the past three weeks around implementing the 3G MDTs into our force and I would like to use it during the implementation process, please could you send us a copy? It seems that there is no one single factor that is lowering the usage of MDTs and your model has covered the majority of factors nicely. - (PM 8, Lancashire Police). 
So although we have a different device (PDA), all these factors are still common throughout, especially socialisation, cultural and management and communication factors. (PM 7, Wiltshire Police).

The existing M-TAM was updated with the findings of this study (see Figure 2). The most influential factors are enlarged and identified by a thick black border, whilst less important factors remain the same as in the original M-TAM. Police forces can therefore see at a glance which individual factors to focus on. The newly emerging factors of local supervision, senior management buy-in and time to implement the project have been incorporated into the existing management style factors. The factors of fit of the technology to the role and task have been placed into a category labelled 'local context'. These two factors are in a new category, as roles and tasks vary in each police force. The new M-TAM is a high-level model that could be applied by any UK police force. It could also be applied outside of the UK, but this needs to be tested in further research.

Insert - Figure 2: The adapted M-TAM

\section{Conclusion}

This paper has investigated the transferability of the M-TAM to other police Forces in the UK. The evidence from this study supports the notion that the M-TAM developed in previous research (Anon, 2011) is transferrable to other police forces with differing types of mobile devices in place. The model should provide a valuable tool for forces worldwide intending to embark on a programme of 'mobilisation' of their information processes. In particular, it should alert them to a wide range of factors needing attention, if such a programme is to be successful. Experts involved in the validation process indicated that the most influential factors affecting adoption of mobile devices lie beyond the 
original technology acceptance model (Davis, 1989), and exist within the wider implementation context. In particular, it highlighted the impact of local management and leadership style. In a policing context, this validates the need to consider external factors within the M-TAM, in order to address the interrelated aspects that are unique to policing. These include a hierarchical command structure and strong bonds amongst police officers. By incorporating a full range of external factors into the m-TAM, Burton-Jones \& Hubona (2006) find that this can improve predictions of technology usage by up to 250 per cent.

This study examined factors commonly encountered by police forces when implementing mobile technologies. The command-culture of policing is an area that can be exploited to maximise adoption, and indeed local supervisory influence was a new factor from the validation process. Sergeants can cascade instructions down the hierarchy to encourage their staff to remain in the field by using their mobile device. Similarly, in organisations with a hierarchical culture it is important that there is a drive from the top of the organisation. Without buy-in from senior management it is unlikely that new technology projects will succeed, and therefore this is a key consideration. Collier et al (2004) argue that cultural barriers in policing need to be addressed to yield appropriate changes in behaviour from the investment of technology. Furthermore, the study shows that the varied and unique roles and activities within policing implies that there is no single approach, and subsequently law enforcement organisations must tailor functionality to suit individual roles and tasks. Content analysis of expert evaluation found that the influence of local supervision and fit of technology to roles and tasks were shown to be the most influential factors, and may relate to the strong cultural barriers apparent within policing.

The existing M-TAM was adapted to incorporate these new factors. Testing and validation of the model in a number of other police forces means it can be applied by other law enforcement and similar organisations as a tool to manage future implementation of technology projects, and in order 
to tackle the barriers to cultural change. The M-TAM has been introduced into a number of environments with a range of mobile devices in place by testing its validity via an expert evaluation. Of course there are limitations to the current study: the relatively small panel of experts may not fully reflect the experiences of all police forces in all cultural and social contexts. We would therefore welcome the input of further forces interested in testing the model in the light of their own experiences. The model also remains untested with regard to the implementation of mobile devices within other national cultures: this is another area for further research. Its validity outside of the emergency services domain also remains an open area for future research. Nevertheless, in the current climate of austerity and the need to maximise value from financial investments, this research is of particular importance.

\section{About the authors}

Dr. Rachael Lindsay $(\mathrm{PhD})$ is a Researcher in the National Audit Office. She was formerly a Research Associate in the Department of Information Science, Loughborough University. Rachael completed a $\mathrm{PhD}$ in the Department in 2010, and her action research study focussed on the impact of mobile technologies on the information and knowledge environment within the Leicestershire Constabulary. It specifically considered the impact on employees and existing information and knowledge intensive processes, and the acceptance of new mobile devices. Her research won several awards and led to the publication of six peer reviewed academic publications of research findings. Her research interests include mobile information and knowledge management, IT adoption and improving data quality with respect to a policing research context.

Prof. Thomas W Jackson (PhD, FBCS) holds a chair in Information and Knowledge Management and is the Director of the Centre for Information Management. His research areas are Electronic Communication and Information Retrieval, and Applied and Theory based Knowledge Management, including his Natural Language Processing Email Knowledge Extraction system (EKE) that has the world's best f-ranking measure. In addition to this, EMOTIVE holds the world's best f-measure for fine grained emotion detection. He is on a number of editorial boards for international journals and has published more than 130 papers in peer reviewed journals and conferences. He has given a number of invited keynote talks throughout the world. He works closely 
with both private and public sector organisations throughout the world and over the last few years he has won over $£ 5.1$ million of funding from sources including EPSRC, Royal Society, Private (e.g. SAP), Public (e.g. Leicestershire Constabulary, The National Archives); KTPs and 3rd Sector (Amateur Swimming Association - predicting swimmer attendance) and won a number of prizes for his research, notably the research undertaken with the Leicestershire Constabulary and the implementation of Mobile Data Terminals in all police vehicles.

Dr. Louise Cooke (PhD, MCLIP, FHEA) joined the Department of Information Science at Loughborough University in 2006, where she currently holds the post of Senior Lecturer, having previously worked as Lecturer at City University, London. She was awarded a PhD in Information Science from Loughborough University in 2004. Louise is Director of Postgraduate Programmes in Information Management at Loughborough and she is also Programme Leader for the MSc Information \& Knowledge Management programme. Louise has a successful track record of gaining research funding from a range of public and private sector organisations and is currently Principal Investigator on the AHRC-funded MAIPLE project. She has undertaken research with a range of policing organisations, including the Leicestershire Constabulary, the National Policing Improvement Agency (NPIA) and the Home Office. Her research interests focus on knowledge management in law enforcement, and the ethical, political and legal aspects of information management.

\section{References}

Adler, M. and Ziglio, E. (1996). Gazing into the oracle: the Delphi method and its application to social policy and public health. London: Jessica Kingsley.

Arnott, S. (12 ${ }^{\text {th }}$ September, 2007). Police need more mobile IT. $<$ http://www.computing.co.uk/computing/news/2198497/policemobile>, [accessed 08.11.07].

Bagozzi, R. P. (2007). The legacy of the Technology Acceptance Model and a proposal for a paradigm shift. Journal of the Association for Information Systems, 8(4), 244-254.

Barry, C. A. (1998). Choosing qualitative data analysis software: Atlas/ti and Nudist compared. Sociological Research Online, 3(3). < http://socresonline.org.uk/3/3/4.html>, [accessed 21.08.12].

Bogner, A., Littig, B. and Menz, W. (eds.). Interviewing experts. Basingstoke: Palgrave Macmillan. 
Bouwman, H. and van de Wijngaert, L. (2009). Coppers context, and conjoints: a reassessment of TAM. Journal of Information Technology, 24(2), 186-201.

Bryman, A. (2001). Social research methods. Oxford: Oxford University Press.

Bryman, A. and Hardy, M. (2009). Handbook of data analysis. London: Sage.

Chan, J. (1996). Changing police culture. British Journal of Criminology, 36(1), 109-134.

Christensen, W. and Crank, J. (2002). Police work and culture in a nonurban setting: an ethnographical analysis. Police Quarterly, 4(1), 69-98.

Collerette, P., Legris, P. and Manghi, M. (2006). A successful change in a police service. Journal of Change Management, 6(2), 159-179.

Collier, P. M.(2006). Policing and the intelligent application of knowledge, Public Money and Management, 26(2), p. 109-116.

Colvin, C. A. and Goh, A. (2005). Validation of the technology acceptance model for police. Journal of Criminal Justice, 33, 89-95.

Davis, F. D. (1989). Perceived usefulness, perceived ease of use, and user acceptance of information technology. MIS Quarterly, 13(3), 319-340.

Flanagan, R. ( $7^{\text {th }}$ February, 2008). The review of policing: final report. $<$ http://police.homeoffice.gov.uk/publications/policereform/Review_of_policing_final_report/flanag an-final-report?view=Binary>, [accessed 25.11.09].

Gallivan, M. J. (2001). Organisational adoption and assimilation of complex technological innovations: development and application of a new framework. ACM SIGMIS Database, 32(3), 5185.

Glomseth, R. and Gottschalk, P. (2009). Police personnel cultures: a comparative study of counter-terrorist and criminal investigation units. Criminal Justice Studies, 22(1), 3-15.

Goldfinch, S. (2007) Pessimism, computer failure and information systems development in the public sector. Public Administration Review, 67(5), 917-929.

Goodhue, D. L. and Thompson, R. L. (1995(. Task-technology fit and individual performance. MIS Quarterly, 19(2), 213-236.

House, E. R. (1980). Evaluating with validity. Beverley Hills, USA: Sage Publications.

Great Britain (2012) Mobile Technology in Policing. House of Commons Committee of Public Accounts Report of Second Session 2012-13. London: The Stationery Office.

Hu, P.J.H., et al. (2003). Examining technology acceptance by individual law enforcement officers: an exploratory study. Intelligence and Security Informatics: Lecture Notes in Computer Science, 2665, 209-222. 
Lai, V. S. (2005) Technology Acceptance Model for internet banking: an invariance analysis. Information and Management, 42(2), 373-386.

Lapointe, L. and Rivard, S. (2005). A multilevel model of resistance to information technology implementation. MIS Quarterly, 29(3), 461-491.

Luen, T. W. and Al-Hawamdeh, S. (2001). Knowledge management in the public sector: principles and practices in police work. Journal of Information Science, 27(5), 311-318.

Anon. (2011). Adapted technology acceptance model for mobile policing. Journal of Systems and Information Technology, 13,398-407.

Miles, M. B. and Huberman, M. (1994). Qualitative data analysis: an expanded sourcebook. London: Sage.

Porter, C. E. and Donthu, N. (2006) Using the technology acceptance model to explain how attitudes determine Internet usage: The role of perceived access barriers and demographics, Journal of Business Research, 59(9), 999-1007.

Reiner, R. (1992). Policing a postmodern society. The Modern Law Review, 55(6), 761-781.

Rogers, E. M. (2003). Diffusion of Innovations, New York: Free Press.

Scriven, M. and Coryn, C. L. S. (2008). The logic of research evaluation. in C. L. S. Coryn and M. Scriven (Eds.), Reforming the evaluation of research. New Directions for Evaluation, 118, 89105.

Tannenbaum, R. and Schmidt, W. (1973). How to choose a leadership pattern. Harvard Business Review, no. 73311, 3-12.

Turner, S. (2001). What's the problem with experts? Social Studies of Science, 31, 123-49.

Venkatesh, V. and Davis, F. D. (2000). A theoretical extension of the technology acceptance model: four

longitudinal field studies. Management Science, 46(2), 186-204.

Venkatesh, V., et al. (2003). User acceptance of information technology: toward a unified view, MIS Quarterly, 27(3), 425-478. 287-309.

Waddington, P. A. J. (1999). Police canteen subculture. British Journal of Criminology, 39(2),

Table 1: Only single research contexts have been used to examine factors influencing police officer acceptance of technology 


\begin{tabular}{|l|l|l|l|}
\hline Hu et al (2003) & US & 280 police officers & Survey \\
\hline Colvin and Goh (2005) & US & 430 patrol officers & $\begin{array}{l}\text { Survey and } \\
\text { observation }\end{array}$ \\
\hline $\begin{array}{l}\text { Bouwman and van der } \\
\text { Wijngaert (2009) }\end{array}$ & Dutch & 106 police officers & Survey \\
\hline
\end{tabular}


Table 2: Experts used within the Research Design

\begin{tabular}{|c|c|c|c|c|}
\hline Purpose & Time period & Method & Sample size & Experts \\
\hline \multirow{2}{*}{$\begin{array}{l}\text { M-TAM } \\
\text { validation }\end{array}$} & \multirow{2}{*}{$\begin{array}{l}\text { September } \\
2009\end{array}$} & $\begin{array}{l}\text { Semi-structured } \\
\text { Interviews }\end{array}$ & $\begin{array}{l}5 \text { police forces: } \\
\text { Cheshire, Essex, Wiltshire, } \\
\text { Lancashire, Humberside }\end{array}$ & $\begin{array}{l}9 \text { project managers of } \\
\text { mobile technologies } \\
\text { from each police force }\end{array}$ \\
\hline & & $\begin{array}{l}\text { Action research } \\
\text { workshop facilitated by } \\
\text { the UK Home Office }\end{array}$ & All 43 UK police forces & $\begin{array}{l}\text { Representatives from } \\
\text { all UK police forces }\end{array}$ \\
\hline
\end{tabular}


Table 3: Content analysis of factors within the M-TAM from a professional review other UK police forces (N.B. figures refer to frequency of factors within the interview transcripts)

\begin{tabular}{|c|c|c|c|c|c|c|c|c|c|c|c|c|c|}
\hline \multirow[b]{3}{*}{ 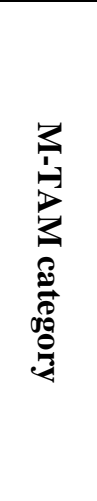 } & \multirow[b]{3}{*}{ M-TAM factor } & \multicolumn{9}{|c|}{ Expert source and Police Force, grouped by device type } & \multirow{2}{*}{\multicolumn{3}{|c|}{$\begin{array}{l}\text { Overall totals and } \\
\text { percentages }\end{array}$}} \\
\hline & & \multicolumn{4}{|c|}{ Handheld devices } & \multicolumn{2}{|c|}{$\begin{array}{c}\text { Handheld and } \\
\text { broadband }\end{array}$} & \multirow[b]{2}{*}{ 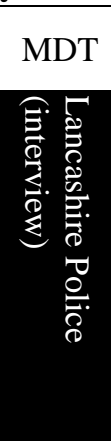 } & \multicolumn{2}{|c|}{$\begin{array}{c}\text { All } \\
\text { devices }\end{array}$} & & & \\
\hline & & 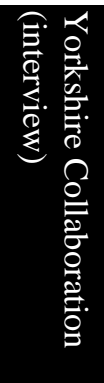 & 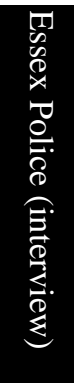 & 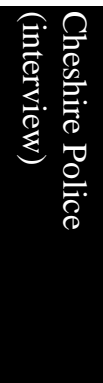 & 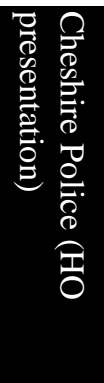 & 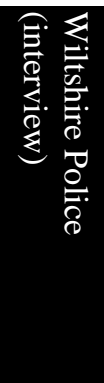 & 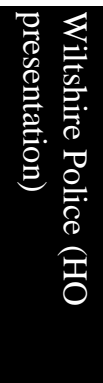 & & 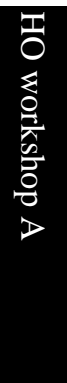 & $\begin{array}{l}\text { T' } \\
\vdots \\
\vdots \\
0 \\
\frac{1}{\hat{\lambda}} \\
0 \\
0 \\
0 \\
0\end{array}$ & 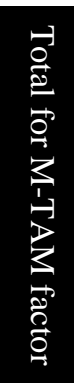 & 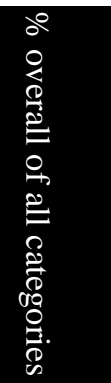 & 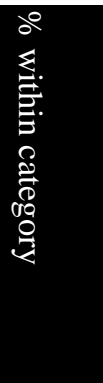 \\
\hline \multirow{7}{*}{ 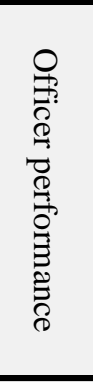 } & Accessing information & 0 & 1 & 2 & 0 & 0 & 0 & 0 & 2 & 0 & 5 & 2.25 & 10.87 \\
\hline & Inputting information & 0 & 0 & 0 & 0 & 0 & 0 & 0 & 2 & 0 & 2 & 0.90 & 4.35 \\
\hline & Data quality & 0 & 0 & 0 & 0 & 0 & 0 & 0 & 2 & 0 & 2 & 0.90 & 4.35 \\
\hline & Officer efficiency & 2 & 5 & 1 & 0 & 0 & 1 & 0 & 6 & 0 & 15 & 6.76 & 32.61 \\
\hline & $\begin{array}{l}\text { Sharing information and } \\
\text { knowledge }\end{array}$ & 2 & 1 & 5 & 0 & 1 & 0 & 0 & 0 & 0 & 9 & 4.05 & 19.57 \\
\hline & Functionality & 3 & 3 & 0 & 0 & 0 & 1 & 0 & 3 & 3 & 13 & 5.86 & 28.26 \\
\hline & Total & & & & & & & & & & 46 & 26.62 & 100 \\
\hline \multirow{4}{*}{ 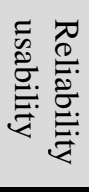 } & Reliability & 1 & 3 & 2 & 0 & 0 & 1 & 3 & 2 & 6 & 18 & 8.11 & 54.55 \\
\hline & Security & 0 & 1 & 0 & 0 & 0 & 1 & 2 & 0 & 0 & 4 & 1.80 & 12.12 \\
\hline & Interface design & 2 & 2 & 0 & 0 & 0 & 1 & 1 & 0 & 5 & 11 & 4.95 & 33.33 \\
\hline & Total & & & & & & & & & & 33 & 14.86 & 100 \\
\hline \multirow{8}{*}{ 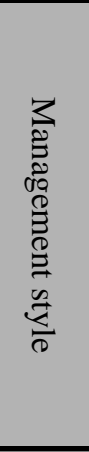 } & Officer level of IT skills & 0 & 1 & 3 & 0 & 1 & 0 & 0 & 0 & 0 & 5 & 2.25 & 5.26 \\
\hline & Level of technical support & 0 & 0 & 0 & 0 & 1 & 2 & 0 & 0 & 4 & 7 & 3.15 & 7.37 \\
\hline & Level of training & 0 & 4 & 4 & 0 & 0 & 5 & 1 & 1 & 9 & 24 & 10.81 & 25.26 \\
\hline & Health and safety & 1 & 1 & 0 & 0 & 0 & 0 & 0 & 0 & 0 & 2 & 0.90 & 2.11 \\
\hline & $\begin{array}{l}\text { Level of officer } \\
\text { involvement }\end{array}$ & 0 & 3 & 0 & 0 & 1 & 5 & 0 & 0 & 14 & 23 & 10.36 & 24.21 \\
\hline & $\begin{array}{l}\text { Level of information about } \\
\text { mobile technology }\end{array}$ & 3 & 5 & 6 & 0 & 1 & 2 & 2 & 0 & 10 & 29 & 13.06 & 30.53 \\
\hline & Officer safety & 2 & 1 & 1 & 0 & 0 & 0 & 0 & 1 & 0 & 5 & 2.25 & 5.26 \\
\hline & Total & & & & & & & & & & 90 & 40.54 & 100 \\
\hline \multirow{6}{*}{ 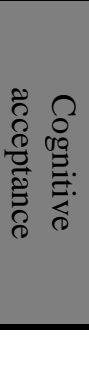 } & $\begin{array}{l}\text { Officer perception of } \\
\text { mobile technology }\end{array}$ & 4 & 3 & 5 & 0 & 0 & 0 & 3 & 0 & 1 & 16 & 7.21 & 33.33 \\
\hline & $\begin{array}{l}\text { Public perception of } \\
\text { mobile technology }\end{array}$ & 1 & 1 & 0 & 0 & 1 & 0 & 0 & 0 & 1 & 4 & 1.80 & 8.33 \\
\hline & Peer influence & 2 & 4 & 1 & 0 & 1 & 3 & 1 & 1 & 5 & 18 & 8.11 & 37.50 \\
\hline & Organisational culture & 0 & 0 & 4 & 0 & 2 & 1 & 1 & 1 & 1 & 10 & 4.50 & 20.83 \\
\hline & Total & & & & & & & & & & 48 & 21.62 & 100 \\
\hline & TOTALS: & 34 & 53 & 64 & 0 & 16 & 36 & 30 & 28 & 94 & 222 & 100 & 400 \\
\hline
\end{tabular}




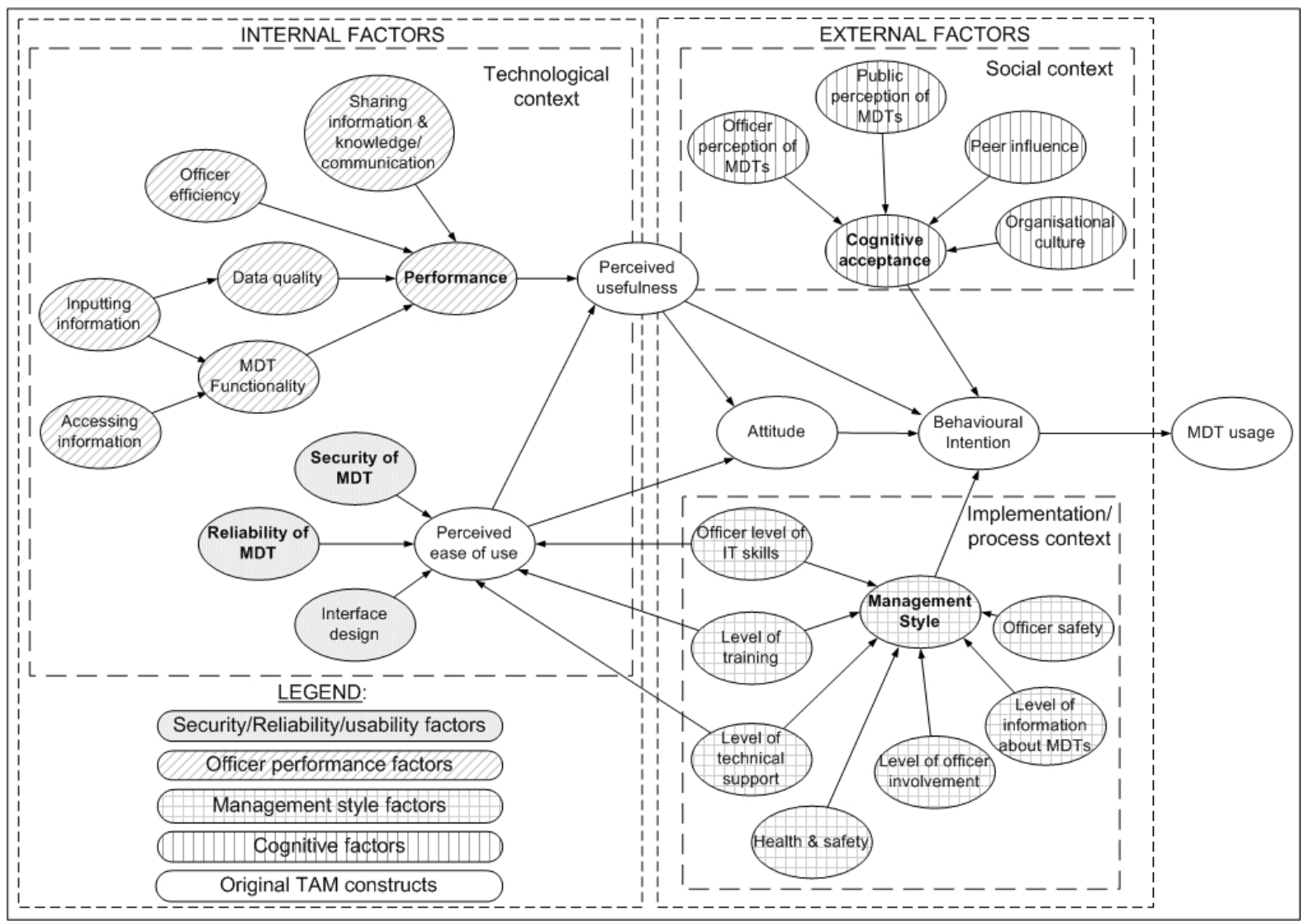

Figure 1: A Mobile Technology Acceptance Model (Anon, 2011; adapted from Lin et al, 2002) ${ }^{*}$

${ }^{*} N B$ - copies of this paper reproduced in black and white will not be able to identify the different coloured categories - the online copy should be viewed for this purpose 


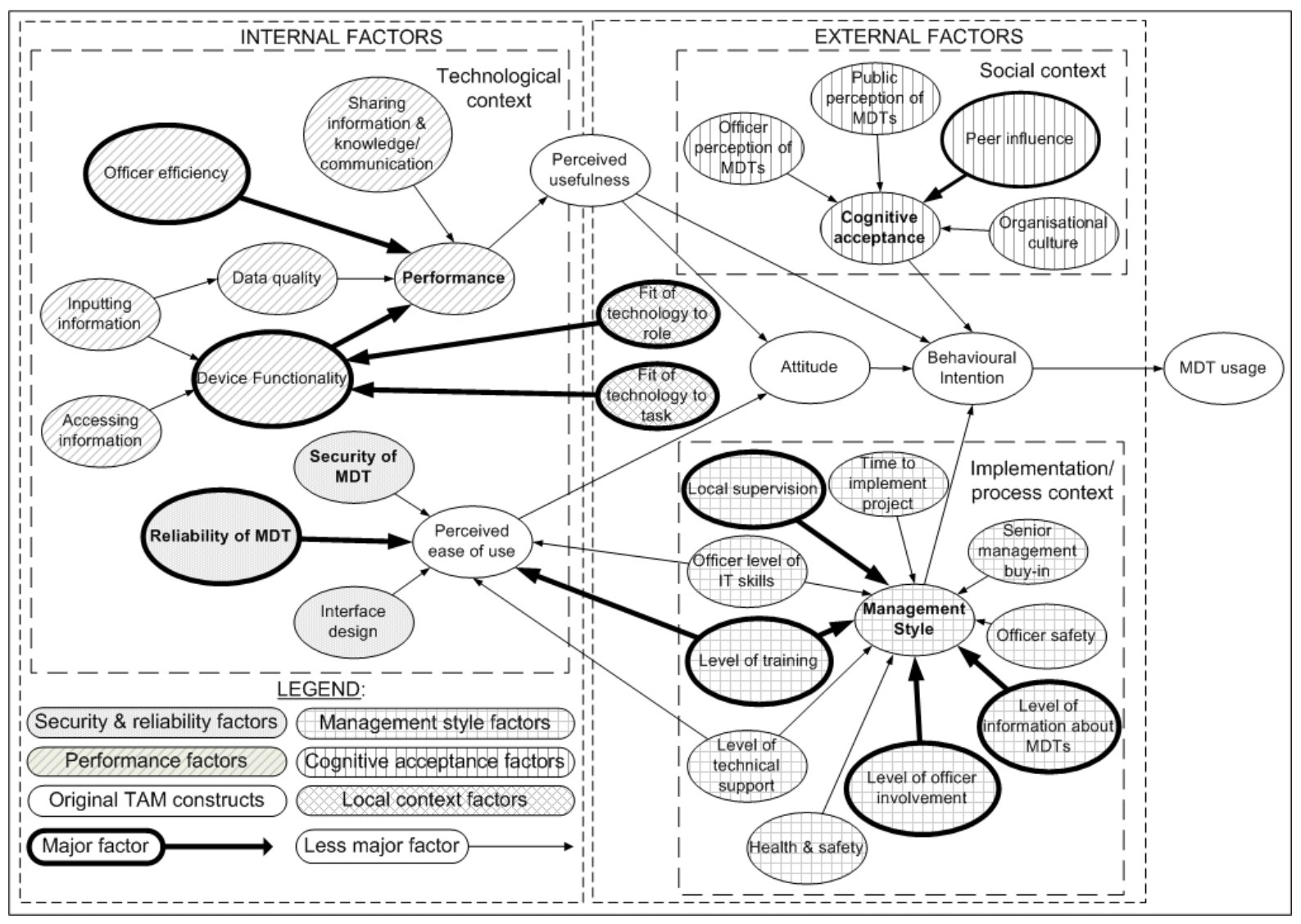

Figure 2: The adapted m-TAM 